\title{
First report of Phytophthora capsici in the Lao PDR
}

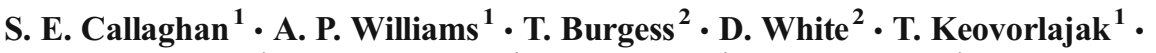

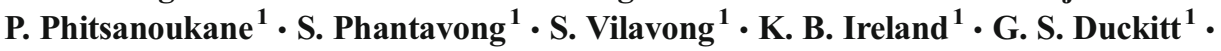 \\ L. W. Burgess ${ }^{3}$
}

Received: 17 January 2016 / Accepted: 30 May 2016/Published online: 8 June 2016

(C) Australasian Plant Pathology Society Inc. 2016

\begin{abstract}
Phytophthora capsici is reported for the first time in the Lao PDR. It was isolated from soil collected from the root zone of wilting red chilli (Capsicum annuum) plants in a polyhouse farm in Paksong district of Champasak province. The wilting chilli plants had typical symptoms of infection by P. capsici including root rot and necrosis of the outer cortex of the stem base. The isolate was identified using morphological and molecular markers. A pathogenicity trial demonstrated that the culture was pathogenic to a local cultivar of chilli seedlings.
\end{abstract}

Keywords Phytophthora capsici · Capsicum annuum · Root rot · Lao PDR · Chilli

Phytophthora capsici is a highly destructive pathogen, with a host range of over 50 plant species (Truong et al. 2012). A majority of its host plants come from the families Solanaceae, Cucurbitaceae and Fabeaceae however P. capsici also causes disease on an increasing list of tropical hosts including cacao (Theobroma cacao), rubber (Hevea brasiliensis), macadamia (Macadamia integrifolia), papaya (Carica papaya), and black pepper (Piper nigrum) (Hausbeck and Lamour 2004; Granke et al. 2012). The pathogen is present in both temperate and

S. E. Callaghan

sophcallaghan@hotmail.com

1 Agriculture Section, Provincial Agriculture and Forestry Office, Thaluang Village, Pakse, Champasak, Lao PDR

2 Center for Phytophthora Science and Management, School of Veterinary and Life Sciences, Murdoch University, Murdoch, WA 6150, Australia

3 Faculty of Agriculture and Environment, The University of Sydney, Australian Technology Park, Eveleigh, NSW 2015, Australia tropical environments, though increased disease severity is correlated with warm $\left(25-30{ }^{\circ} \mathrm{C}\right)$ and wet conditions (Granke et al. 2013; Sanogo and Bosland 2013).

Phytophthora capsici is considered one of the most common and destructive Phytophthora species in Southeast Asia (Drenth and Guest 2004). Despite this, there have been no formal reports of its presence in Lao PDR, due primarily to a lack of scientific work in this area. In contrast, the pathogen has been regularly isolated directly from chilli and other hosts affected by root rot, and also baited from root zone soil, in neighbouring Vietnam (Quang Nam and Lam Dong provinces) and Thailand (Drenth and Guest 2004; Burgess et al. 2008). Since 2012, the authors have regularly observed wilting chilli plants with typical symptoms of Phytophthora root rot at farms on the Bolaven plateau in Champasak province, Lao PDR. This work was part of a continuing program to develop a national checklist of plant pathogens and diseases for Lao PDR.

In June 2015, wilting plants of a local cultivar of chilli (Capsicum annuum) producing red fruits $(5-10 \mathrm{~cm}$ long) were observed in two polyhouses at a large vegetable farm in Paksong district on the Bolaven plateau (1300 m altitude), Champasak province in southern Lao PDR (N: 15 $12^{\prime} 7^{\prime \prime}$; E: $\left.106^{\circ} 17^{\prime} 32.7^{\prime \prime}\right)$. The wilted plants were also stunted and had obvious dark brown to black root rot, including the small lateral roots and the taproot, as well as necrosis (dark browning) of the cortical zone of the stem base (Fig. 1). These symptoms are typical of the symptoms reported for Phytophthora root rot of chilli in Vietnam (Burgess et al. 2008; Truong et al. 2008). The infected plants tended to be clustered in groups of $2-8$ and the symptoms were more commonly observed near the ends of the polyhouse (Fig. 2). Similar symptoms were observed in at least three different cultivars of chilli across several other polyhouses at the farm, although these were not sampled on this occasion (Fig. 3). Approximately 20-30\% of the chilli plants at the farm 


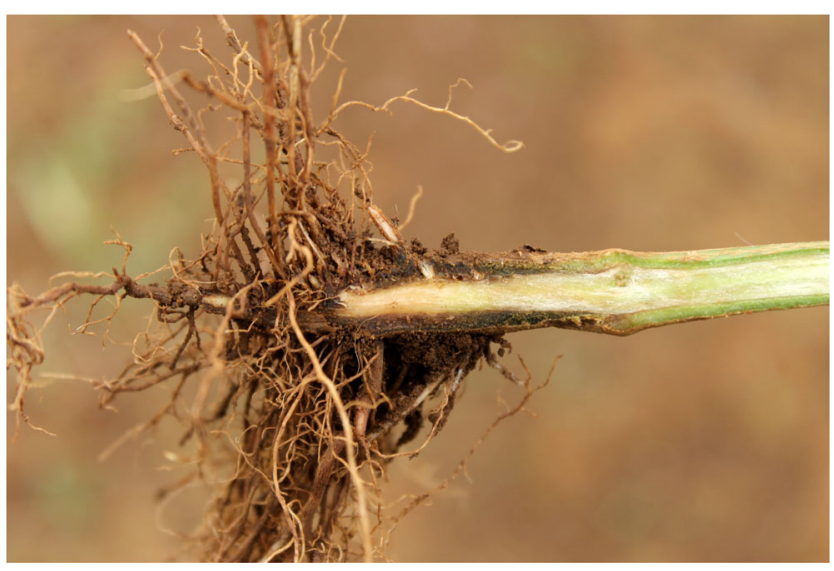

Fig. 1 (Slide 1) Stem and root system of chilli plant with cortical necrosis and root rot, symptoms of disease caused by Phytophthora capsici

showed symptoms typical of infection by $P$. capsici. The crops were grown under plastic mulch and were irrigated through a perforated hose under the plastic. A composite root zone soil sample comprising of sub-samples from under two wilted plants in each polyhouse was collected by shaking the soil from the uprooted plant into a plastic bag, and collecting additional soil from the surface soil from where the plant had been removed. The soil samples were stored in plastic bags at room temperature $\left(20-28{ }^{\circ} \mathrm{C}\right)$ and baited for Phytophthora within two weeks of collection after thorough mixing of each sample.

The soil baiting technique used was based on the methods of Burgess et al. (2008). White rose petals were used as the baits, with one floated in each cup. The negative control consisted of cups with the same quantity of water and a rose petal but no soil. The baits were checked several times each day for the presence of Phytophthora lesions on the petal. Brown lesions appeared on the rose petals from day two onwards. When the lesions appeared the petals were removed,

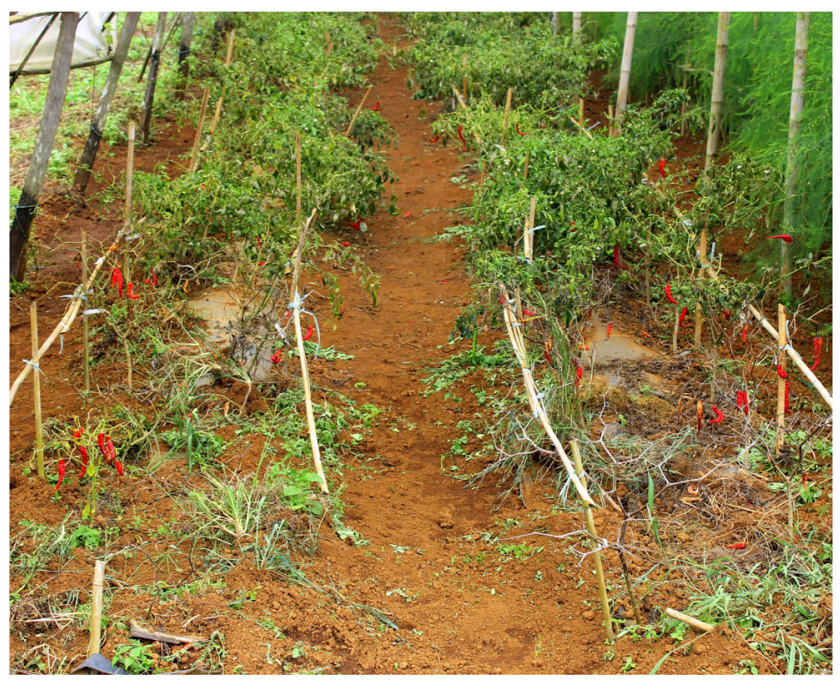

Fig. 2 (Slide 2) Chilli plants at the end of the polyhouse showing severe wilting, leaf yellowing and defoliation, symptoms typical of infection by Phytophthora capsici

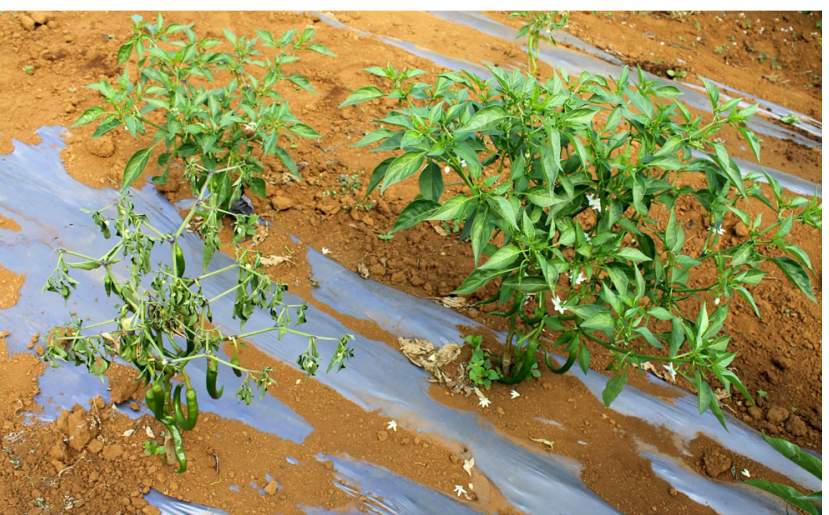

Fig. 3 (Slide 3) Green chilli plant with "green wilt" (left corner), a symptom typical of infection by Phytophthora capsici

washed in sterile $\mathrm{H}_{2} 0$, dipped in $70 \%$ ethyl alcohol (ETOH) for $2 \mathrm{~s}$, then washed in sterile $\mathrm{H}_{2} 0$ once more and damp-dried on sterile paper tissues. Small segments $(3 \times 3 \mathrm{~mm})$ were removed aseptically from the border of the healthy and diseased tissue and plated onto water agar (WA) (Drenth and Sendall 2001) amended with $0.2 \mathrm{~g} / \mathrm{L}$ penicillin and $1 \mathrm{~g} / \mathrm{L}$ streptomycin and incubated in the dark. The plates were checked 2 days later and colonies resembling Phytophthora were hyphal tipped onto carrot agar (CA) (Drenth and Sendall 2001) and incubated in the dark for 7 days. To induce the growth of sporangia, four agar plugs $(3 \times 3 \mathrm{~mm})$ were cut aseptically from the cultures and floated in a small Petri dish $(5 \mathrm{~cm}$ diam.) filled with sterile soil water extract (Drenth and Sendall 2001) and incubated under light at room temperature. Twenty-four hours later the cultures were putatively identified based on morphological markers according to Gallegly and Hong (2008).

A culture was forwarded to the Centre of Phytophthora Science and Management (CPSM) at Murdoch University, Perth, Australia, for identification based on morphological and molecular markers. Morphological observations revealed the sporangia were both papillate and bi-papillate, and predominantly ovoid or ellipsoid, but many other shapes were also observed (Fig. 4). Chlamydospores were not observed.

One pure culture was deposited in the Murdoch University culture collection as MUCC734 (syn. CMA118). DNA was extracted from this culture and the ITS gene region was amplified and sequenced as described previously (Aghighi et al. 2012). The isolate was confirmed as P. capsici (Accession number KT984951) based on $100 \%$ identity of the sequence to those available on GenBank. An additional pure culture was forwarded to the International Collection of Microorganisms from Plants (ICMP) where it was accessioned as ICMP 21114, viability tested and preserved cryogenically in liquid nitrogen.

A pathogenicity test of $P$. capsici on a local cultivar of small chilli was undertaken using a soil inoculation technique (Drenth and Sendall 2001). The inoculum was prepared by soaking millet for $24 \mathrm{~h}$ in water at $5{ }^{\circ} \mathrm{C}$ and then transferring $200 \mathrm{ml}$ into a 

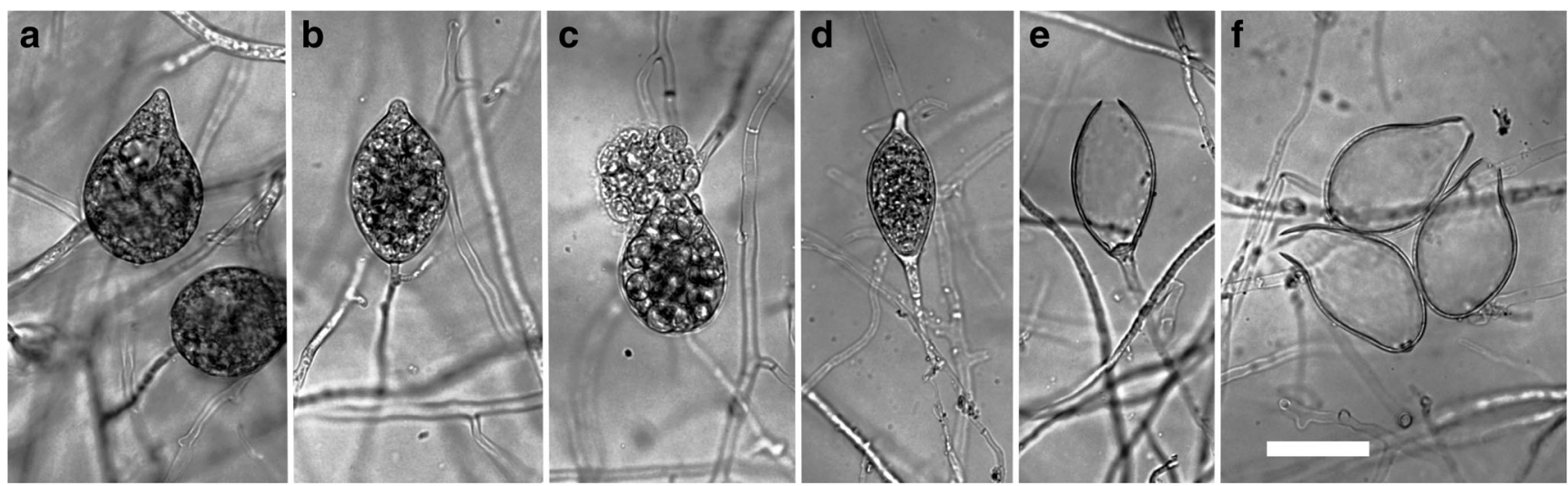

Fig. 4 (Slide 4) Ovoid (a, c, f) and ellipsoid (b, d, e, f) sporangia of Phytophthora capsici, before $(\mathbf{a}, \mathbf{b}, \mathbf{d})$ or after the release of zoospores $(\mathbf{e}, \mathbf{f})$. For $(\mathbf{c})$ the zoospores have encysted before fully leaving the sporangia. Scale bar $=25 \mathrm{um}$

$500 \mathrm{ml}$ Schott bottle. This medium was then sterilised twice in a pressure cooker (Zebra SUS304) at $80 \mathrm{KPA}$ for 90 min on two consecutive days. The millet medium was inoculated with 10 agar plugs $(5 \times 5 \mathrm{~mm})$ from a culture of MUCC734 grown on $\mathrm{CA}$, and incubated for two weeks at room temperature. The bottle was shaken intermittently to ensure thorough colonisation of the medium, and $6 \mathrm{ml}$ of sterile $\mathrm{H}_{2} \mathrm{O}$ was added on two occasions to maintain moisture levels. The inoculum was then added at $3 \%$ by volume to field soil. The soil had been collected from a nearby grassland area that had never been cultivated and was assumed to be free of Phytophthora based on negative baiting results. The control consisted of the same field soil with $3 \%$ by volume of added sterile millet medium.

Ten-day old chilli seedlings (local cv.) were carefully transplanted into four control pots $(10 \mathrm{~cm}$ diam.) and four inoculated pots, with two seedlings per pot. Special care was taken to avoid wounding the roots. The pots were placed outdoors under cover from rain but exposed to the sun and watered once daily. The daily air temperature varied from 24 to $34{ }^{\circ} \mathrm{C}$.

The first wilting symptoms appeared on day 5 and by day 7 all of the seedlings in the inoculated pots had collapsed (Fig. 5). The control seedlings remained symptomless. The infected seedlings had rotted tap roots, some browning of the feeder roots and necrotic stems (Fig. 6). Symptom progression usually involved

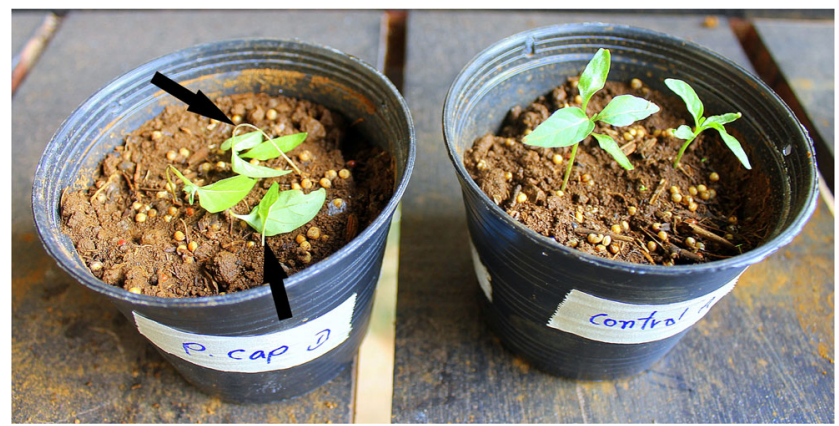

Fig. 5 (Slide 5) Pathogenicity test with inoculated seedlings (left) showing wilted stems and two dropped leaves indicated by black arrows and control seedlings standing upright (right) wilting, followed by leaf drop and finally, death of the seedling. Phytophthora capsici was isolated from the necrotic feeder roots by cutting small segments $(1 \mathrm{~mm})$, surface sterilising as described above and plating onto WA. The results demonstrated that isolate MUCC734 of $P$. capsici can cause disease in the seedlings of a local chilli cultivar. As the isolate was baited from soil however, Koch's postulates were not fulfilled.

This is the first report of $P$. capsici in Lao PDR. Further studies should be undertaken to ascertain the frequency, host range, genetic and morphological diversity of $P$. capsici in the Lao PDR as such information is critical for developing appropriate integrated disease management (IDM) strategies. Meanwhile, the IDM strategies developed in Vietnam for Phytophthora root rot of chilli and black pepper are being promoted (Burgess et al. 2008).

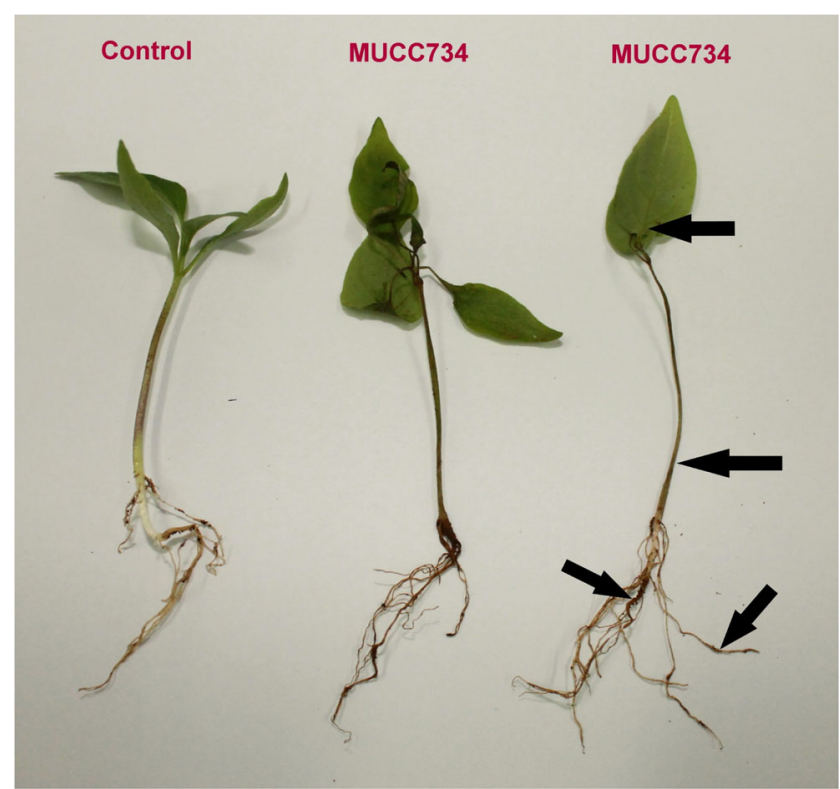

Fig. 6 (Slide 6) Chilli seedlings removed from soil at completion of pathogenicity trial (day 7). Two inoculated seedlings with flaccid leaves, shrivelled stems and tap and feeder root rot indicated by black arrows (centre and right) contrast with healthy control seedling (left) 
Our study demonstrates that the isolated strain of $P$. capsici is virulent towards a local cultivar of chilli producing small red fruit. As $P$. capsici has been confirmed to be the causal agent of disease on numerous hosts besides chilli in adjacent countries Vietnam and Thailand, as well as the Philippines and Indonesia (Drenth and Guest 2004; Truong et al. 2012) it is probable that the pathogen will be associated with additional hosts in the Lao PDR.

Acknowledgments The authors gratefully acknowledge financial and in-kind support from the Center of Phytophthora Science and Management (CPSM) at Murdoch University and the Crawford Fund of Australia. The first and second authors are Australian Government Volunteers for International Development. The third and last authors are volunteer Mentors with the Crawford Fund.

\section{References}

Aghighi S, Burgess TI, Scott JK, Calver M, Hardy GESJ (2012) Phytophthora bilorbang sp. nov., a new species associated with the decline of Rubus anglocandicans (European blackberry) in the south west of Western Australia. Eur J Plant Pathol 133:841-855

Burgess LW, Knight T, Tesoriero L, Phan HT (2008) Diagnostic manual for plant diseases in Vietnam. ACIAR Monograph 129. Australian Centre for International Agricultural Research (ACIAR), Canberra
Drenth A, Guest DI (2004) Diversity and management of Phytophthora in Southeast Asia. Australian Centre for International Agricultural Research (ACIAR), Canberra

Drenth A, Sendall B (2001) Practical guide to detection and identification of Phytophthora. In: CRC for Tropical Plant Protection. Australian Centre for International Agricultural Research (ACIAR), Brisbane, pp 5-38

Gallegly ME, Hong C (2008) Phytophthora: identifying species by morphology and DNA fingerprints. American Phytopathology Society (APS), MN

Granke LL, Quesada-Ocampo LM, Hausbeck MK (2012) Differences in virulence of Phytophthora capsici isolates from a worldwide collection on host fruits. Eur J Plant Pathol 132:281-296

Granke LL, Quesada-Ocampo LM, Hausbeck MK (2013) Phytophthora capsici in the Eastern USA. In: Lamour K (ed) Phytophthora: a global perspective. CABI Plant Protection Series, Oxfordshire, pp 96-103

Hausbeck MK, Lamour KH (2004) Phytophthora capsici on vegetable crops: research progress and management challenges. Plant Dis 88 : 1292-1303

Sanogo S, Bosland PW (2013) Biology and Management of Phytophthora capsici in the Southwestern USA. In: Lamour K (ed) Phytophthora: a global perspective. CABI Plant Protection Series, Oxfordshire, pp 87-95

Truong N-V, Burgess L, Liew EC (2008) Prevalence and aetiology of Phytophthora foot rot of black pepper in Vietnam. Australas Plant Pathol 37:431-442

Truong N-V, Burgess L, Liew E (2012) Cross-infectivity and genetic variation of Phytophthora isolates from chilli and black pepper in Vietnam. Australas Plant Pathol 41:439-447 